\title{
TRABALHO E ESTRANHAMENTO: A DETERMINAÇÃO SOCIAL DA SAÚDE EM ASSENTAMENTOS
}

\author{
WORK AND ESTRANGEMENT: SOCIAL DETERMINATION \\ OF HEALTH IN SETTLEMENTS
}

\section{TRABAJO Y ALEJAMIENTO: LA DETERMINACIÓN SOCIAL DE LA SALUD EN LOS ASENTAMIENTOS}

\author{
Paulo Victor Rodrigues de Azevedo Lira ${ }^{1}$ \\ Pedro Costa Cavalcanti de Albuquerque ${ }^{2}$ \\ Idê Gomes Dantas Gurgel ${ }^{3}$
}

Resumo Conhecer como se organiza o processo de trabalho em qualquer atividade produtiva é essencial para entender os impactos na saúde dos trabalhadores. Esse conhecimento inclui a forma de organização da sociedade, que pode influir no desenvolvimento do ser, como também contribuir para seu estranhamento/ alienação. No estudo buscou-se compreender como se organiza o processo de trabalho do campesinato em dois assentamentos influenciados por lógicas distintas - a do agronegócio e a da agroecologia - e, a partir dessa relação, como ocorre o estranhamento do trabalho e seus impactos na saúde dos assentados. Tratou-se de um estudo de casos múltiplos, baseado em abordagem qualitativa, com a utilização de entrevistas semiestruturadas e grupos focais. O estudo foi realizado entre os meses de janeiro e maio de 2016, em dois assentamentos da Região Metropolitana do Recife. O processamento e a análise dos dados seguiram uma perspectiva que considera a totalidade e a historicidade das relações sociais e sua articulação com os processos sociais particulares. Os resultados revelaram que a condição de estranhamento (e combate a este) ocorre de diferentes formas nos dois assentamentos. Quando influenciado pelo agronegócio, apresenta-se em uma produção especializada, quase exclusiva de mercadorias e com uso intensivo de agrotóxicos. Já em relação à influência da agroecologia, apresenta uma produção diversificada, abolindo o uso de agrotóxicos e com menor intensidade no trabalho.

Palavras-chave agroindústria; agricultura sustentável; pesticidas; saúde do trabalhador; saúde pública.
Abstract Knowing how is organized the working process in any productive activity is essential to understand the impact on health workers. This knowledge is associated with the form how society is organized, which may result in the full development of the being, but also contribute to estrangement/alienation. The study that originated this article aims to understand how is organized the peasantry working process in two settlements, influenced by distinct factors: the Agribusiness and the Agroecology and, from this relationship, the labor's estrangement/alienation and its impacts on the settlers' health. It's a multiple cases study, based on a qualitative approach, using semi-structured interviews and focus groups. The study was made between January and May 2016, in two sets of the Metropolitan Region of the Recife, Pernambuco, Brasil. Data processing and analysis followed a perspective that considers the totality and historicity of social relations and their articulation with particular social processes guided the data processing and analysis. The results show that the condition of estrangement (and the struggle against it) occurs in different ways in the two settlements, but, in both cases, it's related to the settler's health. When influenced by agribusiness, presented in a specialized production, almost exclusively of goods and intensive use of pesticides. Regarding the influence of agroecology, has a diversified production, abolishing the use of pesticides and with less intensity at work.

Keywords agribusiness; agrochemicals; occupational health; public health; sustainable agriculture.

(cc) BY Este é um artigo publicado em acesso aberto sob uma licença Creative Commons. 


\section{Introdução}

O trabalho é uma característica que difere o ser humano dos outros animais, por ter um caráter consciente. Independentemente da forma de organização da sociedade, é condição de existência do ser humano na mediação entre este e a natureza (Marx, 2010; Lukács, 2013).

Na sociedade capitalista, o trabalho, ato que deveria ser finalidade básica do ser social, se converte em meio de subsistência (Marx, 2010; Antunes, 2011). Nesse contexto, engendram-se as condições concretas do trabalho estranhado/ alienado (Entfremdung), ${ }^{4}$ influenciadas pelo desenvolvimento das forças produtivas, das relações de produção, com influência da ideologia burguesa e sua articulação com a consciência. A subsunção do trabalho ao capital favorece a condição de estranhamento que, mesmo originada no processo de trabalho, exerce influência em todas as esferas da vida (Sartori, 2010; Lukács, 2013). O trabalho perde o seu caráter realizador, passando a ser apenas um meio para que o indivíduo supra suas necessidades fora do trabalho (alimentação, moradia, lazer, entre outras, conseguidas por meio do salário). Ocorre, portanto, um estranhamento do produtor com o produto do seu trabalho, com a atividade realizada no processo de trabalho, com o gênero humano, afastando-se de sua atividade consciente livre, estranhando o ser humano do próprio ser humano, estabelecendo-se relações reificadas (Marx, 2010; Iasi, 2011; Lukács, 2013).

Ao se considerar o processo produtivo da agricultura brasileira nos últimos sessenta anos, este atravessou mudanças que agravaram a crise ambiental e social, as quais se fortaleceram com o processo da 'Revolução Verde' e com a consequente consolidação do agronegócio (Thomaz Júnior, 2004a). Trata-se de um processo que impôs pacotes tecnológicos, com uso de agrotóxicos, fertilizantes, adubos químicos, sementes sintéticas, com a crescente implantação da maquinaria, associado ao fornecimento de crédito aos pequenos produtores - fatores estes que aumentaram a dependência do campesinato ${ }^{5}$ ao mercado (Novaes, Mazin e Santos, 2015). O avanço na concentração de terras por parte dos grandes produtores, seguido pela atuação de empresas transnacionais, contribuiu para a expropriação das terras camponesas (Movimento dos Trabalhadores Rurais sem Terra, 2013). Nesse panorama, proletariza-se parcela do campesinato, mesmo que temporariamente, configurando os chamados trabalhadores volantes. A proletarização sazonal é uma característica do campesinato, por fazer parte da superpopulação relativa latente. Mesmo submetido a essas relações, o campesinato manteve autonomia relativa na definição do processo de trabalho, em uma relação contraditória de resistência/dominação (Machado e Machado Filho, 2014; Novaes, Mazin e Santos, 2015).

A produção de origem camponesa tem como característica a organização familiar com posse dos meios de produção, diferenciando-se da relação 
essencialmente capitalista baseada na proletarização, no assalariamento e na acumulação de capital. $\mathrm{O}$ trabalho camponês tem como essência o autoconsumo e a circulação simples de mercadorias para atendimento das necessidades da família - características que não o tornam imune às relações capitalistas que o submetem ao mercado por meio do auferimento da renda da terra e da monopolização do território (Oliveira, 2004, 2007). Essa submissão foi potencializada pela lógica do agronegócio, sendo a estrutura e a dinâmica da relação do campesinato com o mercado determinantes na forma como ocorre a sua (re)produção (Plein, 2010).

No processo de resistência à dominação do capital, incorporam-se as lutas do campesinato, com produção de conhecimento e estímulo a uma práxis contrária à lógica do agronegócio. A agroecologia é uma ciência que busca integrar os saberes históricos dos camponeses com os conhecimentos de diferentes ciências; contrapõe-se à lógica do agronegócio (Caporal e Azevedo, 2011; Guzmán e Molina, 2013). Movimentos sociais do campo apontam a agroecologia como um caminho para o combate ao agronegócio, à opressão e à alienação sofrida pelo campesinato (Movimento dos Trabalhadores Rurais sem Terra, 2014; Novaes, Mazin e Santos, 2015).

Em Pernambuco, a agricultura representou, em 2010, 4,8\% do produto interno bruto (PIB) do estado, com cerca de 900 mil pessoas ocupadas nessa atividade (Instituto Brasileiro de Geografia e Estatística, 2011). O processo saúde-doença é determinado socialmente; no caso do campesinato, apresenta particularidades que se relacionam com a totalidade social. A determinação social da saúde é condicionada por múltiplas determinações oriundas do desenvolvimento do capitalismo, considerando o padrão de produção e reprodução ampliada do capital e suas contradições expressas na dinâmica da luta de classes, por meio da qual o acesso à riqueza socialmente produzida se dá de maneira distinta entre essas classes (Albuquerque e Silva, 2014)

Esse processo evidencia-se especificamente quando relacionado ao uso de agrotóxico pelo número de casos de intoxicações notificadas, apesar da elevada subnotificação (Carneiro et al., 2015). No período de 2007 a 2013, notificaramse 1.506 casos em Pernambuco, associados à intoxicação por agrotóxico de uso agrícola. Do total das notificações por intoxicação, $64 \%$ foram devidas a tentativas de suicídio, das quais $24 \%$ destas ocorreram com trabalhadores do setor agrícola (Pernambuco, 2014).

O estudo aqui apresentado teve por objetivo compreender, sob a orientação da determinação social da saúde, como o estranhamento/ alienação do trabalho ocorre na população campesina de dois assentamentos, influenciados pelos princípios do agronegócio e da agroecologia, bem como as repercussões que essa condição social gera na saúde desses indivíduos. 


\section{Método e instrumentos de pesquisas}

Realizou-se estudo de casos múltiplos. Os dados foram coletados entre janeiro e maio de 2016, inicialmente com informantes-chave, selecionados por sua atuação na agricultura (representantes do movimento social, de organização não governamental ligada à agroecologia, de entidade de direito privado que presta serviços técnicos, de órgão de fiscalização pública, da academia e das lideranças dos assentamentos). Os assentamentos foram selecionados de acordo com o processo produtivo, se agroecológico ou convencional, pela localização próxima ao Recife - o que facilitou as visitas - e pelo contato prévio com as lideranças. A escolha dos entrevistados baseou-se nas informações obtidas com informantes-chave e na concordância dos agricultores em participar da pesquisa. Apresentou-se a eles um termo de consentimento livre e esclarecido, contendo os objetivos, a metodologia e explicações sobre a livre participação e a preservação do sigilo. Os depoimentos foram gravados e posteriormente transcritos na íntegra.

Os assentamentos estudados ficam localizados na zona da mata pernambucana. O assentamento Chico Mendes III conta com cerca de 165 assentados e tem sua produção baseada nos princípios da agroecologia. O assentamento de Natuba conta com cerca de trezentos agricultores trabalhando e residindo na região e tem sua produção influenciada pelos princípios do agronegócio.

Empregou-se abordagem qualitativa, com utilização de técnicas de grupo focal e entrevistas semiestruturadas (Minayo, 2013). As ferramentas de diagnóstico rural participativo (DRP), utilizadas nos grupos focais, são diagramas visuais e interativos que representam aspectos de uma realidade e construídas por um grupo de pessoas em discussão. Cada ferramenta tem usos e procedimentos específicos, mas todas são instrumentos de abstração da realidade (Faria e Ferreira Neto, 2006). As entrevistas semiestruturadas foram realizadas com informantes-chave e com assentados dos dois assentamentos. As entrevistas tinham como algumas questões orientadoras: a descrição do processo de trabalho, os motivos pelos quais aderiu a determinada forma de produção e as consequências do trabalho para a saúde.

Foram feitas dez entrevistas individuais, sete com informantes-chave e três com assentados, e quatro grupos focais. Em Natuba, realizou-se somente um grupo focal devido à baixa adesão dos assentados. Assim, foram efetuadas mais três entrevistas individuais com os assentados a fim de reduzir as perdas pela não realização dos grupos focais. Para garantir o anonimato, os participantes foram denominados pela letra 'S' (sujeito) nas entrevistas realizadas seguidas pelo número correspondente da entrevista. Utilizou-se a letra 'G' quando o depoimento foi originado dos grupos focais, seguido do número do grupo focal. 
O processamento e a análise dos dados foram orientados por uma perspectiva que considera a totalidade e a historicidade das relações sociais e sua articulação com os processos sociais particulares, compreendendo a realidade concreta como síntese de múltiplas determinações (Kosik, 1976). Considerou-se a articulação entre as categorias ${ }^{6}$ totalidade, mediação e contradição. Além disso, levaram-se em conta o processo de trabalho e seus componentes essenciais; a jornada de trabalho; o pagamento recebido e o tamanho do lote; a relação de trabalho e consequentemente a relação com o mercado, considerando-se o fluxo de mercadorias, a dependência do mercado e a dependência de fatores externos; o estranhamento/alienação e a determinação social da saúde.

O estudo aqui apresentado foi aprovado pelo Comitê de Ética em Pesquisa sob certificado de apresentação para apreciação ética n. 44507115.5.0000.5190 e n. do parecer Plataforma Brasil n. 1.363.781.

\section{Processo de trabalho, campesinato e a influência do agronegócio}

O trabalho no assentamento de Natuba é caracterizado por uma produção de base familiar, mas que eventualmente emprega trabalhadores assalariados. A contratação desses trabalhadores não descaracteriza a produção como camponesa, pois esta mantém-se baseada na circulação simples de mercadorias (Oliveira, 2007). O pagamento da força de trabalho assalariada é feito por meio de diárias ou por semana trabalhada, com valores em torno de $\mathrm{R} \$ 300,00$ a R\$ 400,00 por semana. A inserção do trabalhador assalariado inclui uma dimensão diferenciada na análise, sobretudo na diferença da relação de trabalho assumida, já que os camponeses têm a posse do lote e os assalariados não, apesar de a condição de trabalho apresentar semelhanças.

A produção do assentamento é quase exclusivamente de hortaliças para a venda, o que contrasta com a finalidade comumente atribuída à produção camponesa - a qual, segundo Thomaz Júnior (2004b), é destinada à subsistência da família, por meio do autoconsumo e da comercialização do excedente.

A transição da relação de autossuficiência do campesinato para uma dependência do mercado se constituiu diante de um processo histórico em que a separação da indústria camponesa da sua produção na agricultura foi fundamental para gerar a dependência da produção industrial (Luxemburgo, 1970). O campesinato tem necessidades externas ao que é produzido por ele e essa relação pode acarretar uma intensificação do trabalho, em razão, na maioria dos casos, de o preço do produto oferecido pelo camponês ser estabelecido por um agente externo (Wanderley, 1985). Essa dependência é expressa:

(...) que nem a gente não plantava esse salsão. Aí J... disse assim: vocês planta aí, agora o preço é esse. Ele paga os moinho a cinquenta centavos, meu preço vai ser 
esse. Já faz uns cinco ano que a gente planta e bota pra ele, o preço é o mesmo há cinco anos atrás! (S8).

Para Wanderley (1985), na produção de mercadorias não há uma distinção clara entre autoconsumo e excedente. Essa relação sofre mediação determinante do mercado e das necessidades de reprodução da família - fato constatado no assentamento de Natuba, pois em muitas famílias locais não há produção para autoconsumo, somente para venda.

Outro fator determinante para que o trabalho seja majoritariamente voltado para a produção de mercadorias é o tamanho reduzido dos lotes, o que Lustosa (2012, p. 260) caracteriza como "reforma agrária com pouca terra" típica de um "reformismo conservador", com expresso no seguinte trecho de entrevista:

(...) a primeira desapropriação foram 25 hectare, pra você ter uma ideia foram assentadas 85 famílias. As outras áreas foram maiores, porque o pessoal já morava no seu sitiozinho, ficou na faixa de dois, três, quatro, cinco hectare. Se você tivesse um agricultor, com no mínimo cinco ou seis hectare, o que é que ele faria? Plantava o coentro, ele plantava o cebolinho, ele plantava outro tipo de cultura (...). Servia pra vender e servia pra alimentação (S3).

Há uma relação inversamente proporcional entre o tamanho do lote e a autossuficiência dos camponeses - relação associada ao processo de 'reforma agrária' desenvolvido no país, uma vez que este se configura como uma 'política de assentamentos' sem levar em conta as necessidades dos assentados e ainda beneficiando os antigos 'donos das terras' desapropriadas (Miralha, 2006).

O tempo da cultura também é importante para a definição da produção no assentamento. As culturas de curta duração, como coentro e alface, são escolhidas em detrimento de culturas de longa duração, como banana e macaxeira, pela necessidade de comercialização.

A comercialização dessas culturas é feita aos atravessadores, ao Ceasa, a grandes supermercados, e ainda há venda direta em feiras livres. Para garantir a venda e reduzir gastos com o frete, tende-se a priorizar os atravessadores. Dessa forma, mesmo sem ter a posse direta do meio de produção, o mercado define processos relacionados à produção das famílias que, em escala ampliada, terá uma contribuição para a reprodução do capital. Os preços das mercadorias, em sua essência, não são diretamente definidos pelos agricultores; são influenciados pelo seu valor, expresso quantitativamente pelo tempo de trabalho socialmente necessário para sua produção, o que acaba por limitar os ganhos dos pequenos produtores e se agrava ainda mais com a presença de intermediários, que ficam com parte dos rendimentos. 
Oliveira (2007) chama a atenção para a sujeição da renda da terra camponesa ao capital:

O caminho para se entender a presença significativa de camponeses na agricultura dos países capitalistas é pela via de que tais relações não capitalistas são produto do próprio desenvolvimento contraditório do capital. A expansão do modo capitalista de produção, além de redefinir antigas relações, subordinandoas à sua produção, engendra relações não capitalistas igual e contraditoriamente necessárias à sua reprodução. Na agricultura, esse processo de subordinação das relações não capitalistas de produção se dá, sobretudo, pela sujeição da renda da terra ao capital. O capital redefiniu a renda da terra pré-capitalista existente na agricultura. Ele agora apropria-se dela, transformando-a em renda capitalizada da terra. É neste contexto que se deve entender a produção camponesa: a renda camponesa é apropriada pelo capital monopolista, convertendo-se em capital (Oliveira, 2007, p. 40).

Evidencia-se uma relação de 'monopolização do território', pois o capital, mesmo não tendo a posse do meio de produção, subordina a produção à sua lógica (Oliveira, 2004). Situação descrita por Silva Júnior e Machado (2009) ao analisarem a produção de assentamentos de reforma agrária do Movimento dos Trabalhadores Rurais sem Terra (MST) em Pernambuco, onde os assentados que conquistaram a terra de antigos engenhos de produção de cana-de-açúcar mantêm a produção voltada para as usinas canavieiras.

Com o avanço das relações capitalistas no campo brasileiro, acelerado pela 'Revolução Verde', houve mudanças nos processos produtivos, marcados pela inserção de tecnologias e pela expropriação de terras campesinas, reconfigurando suas formas de produção e aproximação do mercado (Oliveira, 2007).

Com a constituição do assentamento de Natuba na década de 1980, foram realizados incentivos por parte do poder público e do Banco Mundial.

Estávamos com a equipe, com um projeto elaborado de irrigação. Foi motor, cano, mangueira - que na época se irrigava com mangueira. Então tudo a gente conseguiu de graça, a fundo perdido pelo Pró-Rural. Quem financiou aqui foi o Banco Mundial, junto do governo do estado na época (G2).

Na contramão do demonstrado por Bianchini e Medaets (2013), que apresentam as ações desenvolvidas pelo Banco Mundial por meio dos programas de desenvolvimento em áreas rurais na década de 1970 e início dos anos 1980 - com temática que abordava a 'inclusão social' e o 'manejo dos solos e águas' como resposta às ações anteriormente desenvolvidas pela 'Revolução Verde' -, as ações em Natuba parecem aprofundar o uso/dependência dos pacotes tecnológicos, como demonstra o trecho de entrevista a seguir: 
De primeiro, quando a economia daqui tava começando, os produto químico era menos. Porque a qualidade da terra era nova. Não era trabalhada. Com o passar do tempo, a gente botando produto químico na terra, aí vai prejudicando a terra. Não fica com aquela saúde (S10).

A inserção de novas tecnologias também trouxe mudanças positivas no processo de trabalho e na saúde dos produtores:

Melhorou muito, porque antigamente era no aguador. (...) Nós começava era onze hora da noite a aguar. Tinha vez que o dia tava amanhecendo a gente ainda tava aguando (...) [Hoje] com um motor de baixa potência, a gente agoa uma área três oitava com trinta minuto. Quer dizer, melhorou muito. Até na cavagem de leirão adiantou, que hoje em dia tem o trator (S8).

Apesar das mudanças positivas causadas pela inserção de tecnologias, as cargas de trabalho (Laurell e Noriega, 1989) permanecem, principalmente relacionadas à extensão da jornada de trabalho: "Esse trabalho de horta é um trabalho que requer de domingo a domingo" (G2).

Dentre as mudanças implementadas, o uso de agrotóxicos tem importante papel. O município de Vitória de Santo Antão, onde está localizado o assentamento, foi o que apresentou maior número de amostras em Pernambuco, com resíduos de agrotóxicos proibidos e acima dos limites permitidos em monitoramento realizado nos anos de 2011 e 2012 (Pernambuco, 2014). Na entrevista, o uso intensivo de agrotóxico é destacado:

Eu dali passo quatro, cinco qualidade [agrotóxicos], cada um tem uma função. Na sementeira sempre é uns produto mais forte. Sempre variando, não uso sempre a mesma coisa. Senão, minha química não vai fazer nada (S8).

A dependência desse modelo, baseado no consumo de insumos químicos e na produção especializada de culturas, está diretamente associada ao ideário do agronegócio, que se reproduz nas ações do Estado - como a extensão rural, que hegemonicamente cumpriu um papel 'domesticador' (Freire, 1983). Na fala de um trabalhador de um órgão de fiscalização, esse aspecto é expresso:

(...) eles pensam que a saúde tá muito boa, porque a maioria é assim. Aí: “Dr., há quarenta anos que eu trabalho com isso, não tenho medo de veneno". Eles são muito ignorante. [Eu digo:] "Mas, rapaz, isso aqui faz mal (...) você pode ter uma doença dentro do seu organismo (...) isso causa câncer." Ele fica com certo receio, depois, por acharem que estão fortes, continuam e aumentam de novo. É um ciclo. E eles, infelizmente, o homem só gosta de visar o lucro (S6). 
Essa postura reforça posições referendadas a partir do 'ato inseguro', em que a culpa pelo uso de agrotóxicos, intoxicações e acidentes de trabalho é atribuída exclusivamente aos agricultores, sendo desconsiderado o processo sócio-histórico em que essas relações se construíram.

\section{Processo de trabalho, campesinato e a influência da agroecologia}

No assentamento Chico Mendes III, a força de trabalho é de origem familiar, composta em sua maioria por adultos, com faixa etária acima dos quarenta anos, e idosos. Há uma baixa participação de filhos, netos e sobrinhos dos assentados na produção, conforme também evidencia Barbosa Júnior (2013).

A influência dos princípios da agroecologia é percebida nas alterações no processo de trabalho e na relação dos agricultores com a natureza, conforme expresso na fala: "Não tenha dúvida que os agricultores que já interiorizaram os princípios da agroecologia eles têm uma relação melhor com a natureza..." (S1). Apesar das mudanças na relação com a natureza e do não uso de agrotóxicos no processo de produção, o apoio governamental é questionado, com cobranças em relação a mais incentivos para a produção de base agroecológica.

$\mathrm{O}$ assentamento produz variadas hortaliças e frutas e há também a criação de animais. Esse processo recupera relações baseadas no conhecimento dos agricultores em diálogo com outras áreas de conhecimento científico e expressa as mudanças realizadas pela transição agroecológica. Martins (2009) afirma que a agroecologia se fundamenta em novas experiências na relação entre humanos e a natureza, abordando mudanças no processo produtivo em que, ao contrário do latifúndio, "se produz alimentos saudáveis e se recupera e preserva a natureza (...). Com base nas características do ecossistema local (...) se reorganiza o trabalho e se constrói relações de produção não alienadas" (Martins, 2009, p. 37). A agroecologia também é entendida como valorização do saber campesino, retomando a cultura de produção de alimentos sem os insumos químicos da 'Revolução Verde' (Machado e Machado Filho, 2014).

A produção do assentamento tem como finalidade o autoconsumo e a venda de parte excedente. O autoconsumo é potencializado pela variedade das culturas produzidas, o que indica melhor qualidade na alimentação, dependendo menos da compra no mercado, sem excluí-la.

A venda da produção ocorre em feiras livres agroecológicas e 'convencionais' e também porta a porta, mas com variação de preço: “Na feira orgânica a gente tem o preço agregado. Pra vender na porta não podemos vender naquele preço da feira, senão vamos perder o cliente" (G3).

O tabelamento dos preços dos produtos agroecológicos e a venda direta nas feiras são mecanismos que minimizam a submissão do camponês ao mercado. Apesar disso, não são todos os assentados que se deslocam para as feiras; parte destes paga frete ao grupo que comercializa a produção. 
Apesar da maior autonomia no processo de trabalho, na realização pessoal dos assentados, na obtenção do lucro e no consumo da produção, a renda obtida com a venda dos produtos tem característica de complementariedade, não sendo a fonte exclusiva de ganho:

Toda semana, mesmo eu não indo pra feira, é setenta, sessenta, tem semana que é cem reais que apuro das minhas hortaliça, mandando pelos companheiro que vai pra feira. Já ajuda muito na minha renda. Dá pra pagar uma conta de luz. Se eu quero comer uma carne de boi, eu vou lá e compro (G3).

O trabalho assalariado de algum membro da família e as aposentadorias apresentam relevância:

Eu trabalhava até fora, eu fazia uma diária (...) quando eu vim pra cá, não era aposentada e não tinha outra renda (...). Mas eu creio que Deus vai me ajudar e eu vou me aposentar e ele [companheiro] não vai precisar mais estar a semana todinha trabalhando. Ele vai trabalhar aqui dentro (G3).

Observou-se uma dependência, expressa na necessidade de renda alternativa, externa ao processo de trabalho desenvolvido no assentamento. Contudo, as relações baseadas nos princípios da agroecologia modificaram o processo de trabalho, com mudanças práticas relacionadas ao uso de adubos orgânicos, sementes crioulas, além de técnicas que favorecem um trabalho mais confortável para os assentados. Essas mudanças alteraram a forma de os agricultores compreenderem as relações sociais no assentamento e no âmbito da sociedade, indo ao encontro do analisado por Mazalla Neto (2015), que destaca o potencial emancipatório dos assentamentos ao se mostrarem "como espaços sociais concretos, territórios que passaram a construir novas formas de organização social, outras experiências de trabalho e relação com a terra" (Mazalla Neto, 2015, p. 231-232).

Adotar os princípios da agroecologia não significou, no caso dos assentados de Chico Mendes III, um incremento substancial na renda. É preciso lembrar que o campesinato, com suas características específicas tratadas anteriormente, situa-se na superpopulação relativa latente, onde se mantém, em geral, em condições de vida e renda abaixo da classe trabalhadora. Mesma situação do assentamento de Natuba, que adotou o modelo do agronegócio. Isso não quer dizer que a agroecologia tenha uma baixa produtividade como os defensores do agronegócio propagam; ao contrário, já há numerosos relatos na literatura apontando um aumento da produtividade em sistemas agroecológicos. Dentre eles, destacamos o estudo de Souza e colaboradores (2007). 


\section{Estranhamento e determinação social da saúde}

A crescente subordinação ao mercado e a sujeição da renda da terra camponesa ao capital potencializam a condição de estranhamento e têm repercussões além da esfera econômica na vida dos assentados, comprometendo suas condições de vida e saúde. Lukács (2013) caracteriza o processo de estranhamento como histórico e social, refutando uma abordagem desse conflito social como uma condição humana universal.

Nos assentamentos estudados, as relações de trabalho estabelecidas são baseadas no trabalho familiar, com os assentados tendo posse dos meios de produção. Para Marx (1978), essa relação de trabalho não estaria subsumida ao capital, pois a forma de produção dela não se dá por meio de uma relação assalariada de trabalho, em que o trabalhador não possui o meio de produção, sendo a finalidade principal a extração de mais-valia. Lukács (2013) analisou uma forma de estranhamento originada no processo de (re)produção na sociedade capitalista que tem como essência a reprodução ampliada do capital, consequentemente a subsunção do trabalho ao capital. Diante disso, (re) afirma-se o que Oliveira (2004) elabora:

A análise da agricultura, especificamente a brasileira, neste final de século (XX) deve ser feita no bojo da compreensão do desenvolvimento capitalista em nível mundial. Isso passa pela compreensão desse desenvolvimento como sendo contraditório e combinado, ou seja, ao mesmo tempo em que avança reproduzindo relações especificamente capitalistas mais avançadas, gera também, igual e contraditoriamente, relações não capitalistas de produção e de trabalho, como, por exemplo, as relações camponesas (...) todas necessárias a sua lógica de desenvolvimento (Oliveira, 2004, p. 40).

Em Natuba, observaram-se diferenças nas relações de trabalho dos assentados e dos trabalhadores assalariados do assentamento, expressas na descrição de um assentado:

Os trabalhador têm horário. Chega seis e meia, pra sete horas pegar no serviço. É de sete às onze. Para pra almoçar, aí pega de uma às cinco (...). Quem é proprietário ele é que faz o horário dele. Porque se eu trabalho pra eu, aí eu chego cedo, vou-me embora cedo, saio tarde (S10).

Evidenciou-se 'maior autonomia' no controle da jornada de trabalho por parte dos assentados, apesar de terem que, a depender do período e do preço das mercadorias, intensificar e prolongar suas jornadas além da jornada dos assalariados. 
A escolha pelo trabalho no assentamento por parte dos assalariados expressa as relações de estranhamento caracterizadas por Marx (2010), em que a finalidade básica não é o atendimento de uma carência, mas um meio de satisfazer necessidades fora do trabalho.

O motivo [do trabalho assalariado] é o dinheiro. Ganha o ganho mais. Porque não querem ficar em cima daquele salário. Ele questiona isso. “Oxe, eu vou trabalhar fichado [com carteira assinada], vou ganhar oitocentos reais, vou nada! É melhor ficar aqui" (G2).

Existe a cisão entre os trabalhadores e sua produção, aparecendo o processo de trabalho e consequentemente a produção estranhada dos trabalhadores, ou seja, próximo ao trabalho alienado, repercutindo na subjetividade deles.

Para os camponeses do assentamento, o trabalho não se desenvolve a partir de seu caráter genérico, como uma atividade consciente livre. Mesmo engendrado sobre relações de trabalho que não são essencialmente capitalistas, estas sofrem determinações centrais da totalidade social, havendo apenas autonomia relativa. Assim, configura-se alienação do trabalho em Natuba, pois o trabalho é somente um meio para adquirir renda, não realiza o camponês como indivíduo. A relação com o mercado e com o Estado é marcante no processo em Natuba.

No assentamento influenciado pelos princípios da agroecologia, o consumo da produção, a diversidade de culturas produzidas, a venda direta em feiras agroecológicas, a relação com o Estado e a dependência de renda externa mostram-se expressões concretas e contraditórias da relação de estranhamento (e seu combate).

Um aspecto a ser destacado é a relação dialética entre ideologia e estranhamento. A ideologia ${ }^{7}$ é um aspecto importante da superestrutura das sociedades que justifica a práxis social. A ideologia burguesa atua como falsa verdade, utilizada pela classe dominante para manutenção de seu status quo (Marx, 2010). Percebe-se a organização das relações materiais capitalistas no nível da consciência dos assentados, sobretudo na reprodução de necessidades, como por exemplo a dependência do uso de agrotóxicos em Natuba:

Vamos pro IPA [Instituto Agronômico de Pernambuco], outras pessoas que vêm [iniciativa privada], faz curso com a gente, então explica como devemos trabalhar com aquela, com essa cultura pra gente não ter tanto prejuízo na doença (...) eles fala que é pra gente combater ela de pequeno, é de nova, porque falam: quando uma criança nasce, qual é a primeira coisa que tem que fazer? Vacinar [utilizar agrotóxico]. A mesma coisa é a agricultura, eu mesmo cumpro a minha parte, agora só que a maioria não cumpre... Agora aqueles que não cumpre, sofre (S8). 
É estabelecida a relação entre materialidade e o processo de consciência dos agricultores, moldado ao modelo hegemônico do agronegócio. Essa dependência se estruturou historicamente, atendendo às necessidades de reprodução do capital. Apesar dos estudos sobre adoecimento e morte causados pelos agrotóxicos e da alarmante subnotificação de casos de intoxicação (Carneiro et al., 2015), os órgãos técnicos de extensão rural comparam o uso deles com um fator protetivo (vacina) - logo, se deduz com poucos riscos à saúde, discurso e prática incorporados pelos assentados.

Outro sujeito critica o uso de agrotóxicos, inclusive relacionando-o ao adoecimento dos agricultores, apesar de permanecer em um paradigma hegemônico baseado no 'uso seguro': “É ver a evolução, ver os problemas também. Veio mais produção, veio mais problema, veio mau uso de agrotóxicos (...). Veio a doença no agricultor. Pelo uso indevido do agrotóxico" (S3).

Evidencia-se a emergência da primeira forma de consciência (Iasi, 2011) com a explicitação ideológica de um modelo que tem em sua concretude a subordinação do campesinato ao mercado. O processo de construção dessa forma de consciência é essencial para uma condição de estranhamento, e suas repercussões ultrapassam as esferas produtivas, causando impactos em diversas esferas da vida, inclusive na saúde. Porém, isso não quer dizer que os assentados expostos às contradições da realidade não possam atingir outro nível de consciência e transformação da materialidade.

Em Chico Mendes III, observou-se uma dimensão coletiva de consciência sendo expressa: "Nós estamos aqui através do movimento, através da bandeira do MST (...). Aonde o MST está a bandeira da gente..." (G3). Os assentados se identificam como movimento, logo, têm uma organização para além de sua revolta individual, abrindo uma possibilidade nova, a transformação de relações que antes pareciam intransponíveis na primeira forma de consciência. Segundo Iasi (2011), a consciência em si emerge desse processo de articulação coletiva, mesmo que o objetivo final ainda seja a conquista no âmbito individual. No assentamento, a luta pela terra iniciada em 2004 parece ter sido decisiva nesse processo (Nunes da Silva et al., 2009).

Destaca-se a importância da ideologia no processo de consciência, que pode ter uma característica de manutenção do status quo da classe dominante, mas também de superação. Lessa (2007) ressalta:

Como todo complexo social, a ideologia também passa por um processo de desenvolvimento. Nesse processo, o surgimento das classes sociais é um momento fundamental. A partir do surgimento da luta de classes, a ideologia deve não apenas justificar, tornar razoável, operativa a práxis cotidiana, mas também fazê-lo de modo a atender aos interesses de classe. O ser das classes, e os conflitos entre elas, passam a permear a ideologia; e, ao mesmo tempo, a luta de classes tem na ideologia um de seus momentos mais importantes, já que ela é decidida, em última 
instância, no momento em que uma sociedade se nega a objetivar determinados valores e ideações em favor de outros valores e finalidades (Lessa, 2007, p. 33).

Assim como órgãos técnicos, públicos e privados exercem influência sobre as ações desenvolvidas em Natuba, o MST também busca alterar o processo de trabalho influenciado pela lógica dominante.

A mudança no processo produtivo, com o conhecimento sobre os prejuízos do uso de agrotóxicos e sua relação direta com a saúde, é expressa na seguinte entrevista da liderança do assentamento:

Quando você planta e vê ficando pequenininho, que estão morrendo, você bota um veneno, um adubo. Aquele adubo sobe ele. Subiu, ficou bonito, você vende. Agora, daqui a um ano, dois anos, ou antes mesmo, a terra está destruída porque não tem força, porque você matou aquele local que você tá trabalhando. E aqueles vivente que comeu do seu prantio? Por dentro, vai criar um câncer! (S4).

Destaca-se a articulação entre o complexo da ideologia, o processo de consciência e o estranhamento (e seu combate), todos com a mediação determinante da realidade concreta, influenciando no processo saúde-doença dessas populações. Ou seja, a liderança de Natuba apreende que o uso de agrotóxicos no processo produtivo é prejudicial tanto para a saúde de quem irá consumir quanto para o solo. Assim, a realidade concreta impõe um trabalho alienado, com o objetivo de manter as condições materiais de vida por meio da venda das mercadorias que não realiza o agricultor, trazendo repercussão para a saúde e o ambiente.

Maior autonomia no trabalho é destacada, sobretudo no assentamento de base agroecológica. Os assentados comparam as relações atuais de trabalho com experiências de trabalhos assalariados executados anteriormente. Em geral, quando feita a comparação, o trabalho assalariado é descrito como uma experiência desrealizadora, degradante, enquanto a experiência no assentamento aparece com um sentido positivo, com mais autonomia e liberdade, o que se expressa no seguinte trecho de entrevista:

O trabalho fichado a gente trabalha pra os outro. Somo escravo do trabalho pra os outro. E aqui dentro estamos trabalhando pra nós. A gente tá trabalhando a hora que quer, faz o que quer no nosso roçado. A gente vende, sai daqui com o nosso prantio pra vender na feira, nas ruas (Gl).

Outro trecho ressalta o caráter aviltante do trabalho assalariado desenvolvido antes do período do assentamento e durante parte dele: 
Amanhecia o dia sufocada dentro de um elevador pra trabalhar pra seu fulano, ganhava setenta reais por dia, hoje se eu ganhar dez conto eu sou mais feliz. Porque eu tinha que lavar o banheiro de seu fulano, com licença da palavra, cagava no chão e eu tinha que limpar, eu tinha que comer sentada no chão (...) isso entristece minha alma. Então, pra mim foi feio, horroroso trabalhar pra elite (G1).

Mazalla Neto (2015) relata o potencial emancipador do trabalho segundo os princípios e práticas da agroecologia, apesar de reforçar sua parcialidade, ressaltando que a emancipação humana só se daria com a ruptura e a transformação da sociedade em sua totalidade. O autor enfatiza que a construção das experiências agroecológicas se dá em contraste com as experiências degradantes vivenciadas anteriormente, impulsionando novas formas organizativas da (re)produção, corroborando o observado em Chico Mendes III. A negação das experiências degradantes vivenciadas potencializa a afirmação das práticas agroecológicas.

A respeito da relação dos assentados com sua produção, existem diferenças entre os assentamentos. No que produz sob influência do agronegócio, a relação está majoritariamente associada à produção para venda (produção da mercadoria pelo seu valor de troca). Pouca é a funcionalidade da produção com objetivo de consumo dos próprios assentados (produção pelo valor de uso): “Não, não [se consome a produção]. Eu mesmo só vou comer um pé de alface quando vou no comércio (...). Aquele restaurante selve-serve aí bota uma saladinha" (G2).

Já no assentamento influenciado pela agroecologia, parte da produção é destinada para o autoconsumo e o excedente comercializado:

A gente olha que foi uma luta pra gente conseguir, mas valeu a pena. A gente hoje tá comendo algo que não é com veneno, que é das própria mão da gente, que os filho da gente vai se alimentar (G3).

Me enche de alegria de hoje eu poder dizer que nós planta orgânico (...). Nós estamos levando pra sociedade a se alimentar de um produto de boa qualidade (G1).

O processo de trabalho e a relação de exteriorização do trabalho (Lessa, 2007; Lukács, 2013) impulsionam relações menos dependentes na produção de base agroecológica e contribuem para o estranhamento segundo a lógica do agronegócio. A finalidade quase exclusiva na produção de valores de troca, mesmo que voltada para a subsistência familiar, modula os assentados a procurarem formas mais rápidas e econômicas de produção. Essa relação pode ser decisiva no uso de agrotóxicos e no adoecimento dos assentados.

Os depoimentos reforçam a falta de orientação nas casas que vendem agrotóxicos sem alertar para os perigos oriundos do uso. Também reforçam a 
existência do adoecimento pelo uso de agrotóxicos, principalmente os assentados mais 'antigos', que utilizavam os produtos sem tantas 'preocupações'. O cuidado só se torna mais presente a partir da ocorrência dos casos: “Nós temos o presidente da cooperativa aqui, tem um problema seríssimo (...). E só bota que foi o uso de agrotóxico. Agora já tem um maior cuidado, mas de primeiro o caba pegava de bermuda, descalço" (S3).

No assentamento que tem a produção de base agroecológica, algumas entrevistas expressaram a compreensão sobre os malefícios ocasionados pelo uso de agrotóxico, ultrapassando a esfera do indivíduo que produz, com falas relacionando a saúde do ambiente, da família e das pessoas que irão consumir a produção. Não se desprezou a dimensão da comercialização, mas mesmo nela havia a preocupação com a saúde de quem se alimentará.

Mazalla Neto (2015) ressalta que o domínio do processo produtivo, com a utilização de técnicas que diminuam a dependência do mercado, contribui para o combate do estranhamento nos assentamentos. Isso se confirmou nas relações desenvolvidas no assentamento que tem influência da agroecologia, onde se observou menor dependência no tocante ao mercado, potencializado por uma alimentação mais saudável e maior autonomia do processo de trabalho em uma relação diferenciada com o território, explicitada pelo maior cuidado com a saúde em seu conceito ampliado (Batistella, 2007).

Apesar das diferenças expostas, o processo se constrói de maneira contraditória nos dois assentamentos. Uma semelhança entre os dois processos de trabalho é a diminuição ou ausência de jovens das famílias camponesas nas atividades ou morando nos assentamentos. Eles migraram para a cidade buscando, no assalariamento, sua forma de subsistência - o que pode ser relacionado a diversos fatores, dentre eles a instalação de indústrias na região e a desvalorização do campo, como ficou expresso na fala do assentado em Natuba: "Vitória industrializou-se, inclusive aqui em Natuba nós temos as indústrias. Muitos filhos do agricultor não convive mais dentro da agricultura. Prefere ser empregado numa fábrica do que viver na agricultura" (S3). E no desejo de uma agricultora em Chico Mendes III:

Ser alguém na vida o amanhã. Um alguém que eu não fui, que eu não sou. Eu não quero isso pros meus netos [trabalhar na agricultura]. E tenho certeza que o R..., meu neto mais velho, a S... e o J..., eles não chegam perto disso aqui... Eu não quero o amanhã meus netos dentro do mato com uma enxada (G3).

Nesse último depoimento, emergem as contradições presentes na realidade dos assentados. Mesmo tendo um processo de trabalho mais autônomo, consciente, isso não se manifesta no desejo de continuidade para as gerações futuras da família, aparecendo a vida e o trabalho no assentamento como desvalorização do ser. Essas características explicitadas na fala da entrevistada 
expressam as dificuldades concretas de produção e reprodução social das famílias no assentamento, que apesar de apresentarem características que os diferenciem qualitativamente do trabalho segundo os princípios do agronegócio, indicam a imposição de limitações na vida dos assentados, chegando a vida no assentamento a não ser desejada para seus filhos e netos. Também são explicitados aspectos ideológicos, que caracterizam o trabalho no campo como atrasado, precário, o que favorece, em nível de aparência, a cisão entre campo e cidade.

Porém, no mesmo grupo, podemos perceber a dimensão individual da consciência que vai sendo modificada em articulação com sua dimensão coletiva, ou seja, não há uma uniformização do pensamento, apesar de haver bandeiras de luta em comum. No desejo de outra assentada de Chico Mendes III:

Tenho dezessete neto, dois bisneto, e meu sonho era que eles viesse para o campo. Não será o campo que deixa de dar dignidade, o homem pode ser formado no campo, pode trabalhar na terra, não é vergonhoso (...). Gostaria muito que não só dois ou três, que meus dezessete neto tivesse essa oportunidade que eu tive, de ser liberta, de não trabalhar pra elite. Eles trabalhar, fazer o que gosta, o que quer, ter essa liberdade de ir e vir, montar no cavalo, pescar de açude. Ter essa liberdade não tem nada que pague (G3).

Apesar das diferenciações nos processos produtivos, alguns problemas de saúde são comuns aos assentamentos. A persistência de doenças infectoparasitárias, com destaque para a esquistossomose em Natuba (Leal Neto et al., 2012), doenças osteomusculares relacionadas ao trabalho (DORT) e o aumento das doenças e agravos não transmissíveis (DANT), com evidência para hipertensão e diabetes, são aspectos que aproximam a realidade e a dificuldade no acesso a direitos básicos, como saneamento e acompanhamento regular das famílias pelos postos de saúde, por exemplo.

Albuquerque e Silva (2014) analisam como a construção do processo saúde-doença é determinado socialmente - ou seja, a saúde dos assentados e a construção de 'hábitos saudáveis' não são produtos exclusivamente dos indivíduos, estando diretamente associadas à apropriação das riquezas que são socialmente produzidas e à relação que esses indivíduos têm na complexa divisão social do trabalho. Dessa forma, a saúde é determinada socialmente para diferentes grupos, de caráter distinto e articulados em uma mesma sociedade.

Ao se compreender a saúde como máximo desenvolvimento das potencialidades do ser humano, os dois casos estudados limitam esse desenvolvimento entre os assentados. No assentamento de base agroecológica, a presença do autoconsumo, a variedade de culturas e a compreensão de que o trabalho está produzindo mercadorias que promovem a saúde da população da cidade - que irá se alimentar sem agrotóxicos - revelam um caráter de superação parcial da 
alienação do trabalho em Chico Mendes III, uma vez que as determinações do mercado e a baixa renda ainda estão presentes no assentamento. Já no assentamento de Natuba, as mercadorias produzidas exclusivamente para venda e a subordinação do campesinato às tecnologias impostas pelo modelo do agronegócio para sua reprodução social e às determinações do mercado caracterizam maior grau de alienação do trabalho e, consequentemente, menos saúde.

\section{Considerações finais}

Ao comparar os processos de trabalho segundo lógicas distintas, o agronegócio e a agroecologia, observou-se que ambos estão inseridos no modo de produção capitalista e mostram, na lógica contraditória do capital, as formas de resistência/dependência do campesinato a esse modelo.

A relação entre o processo saúde-doença e o trabalho nos assentamentos estudados é determinada de acordo com a forma de (re)produção dos assentados em articulação com a sociedade. Portanto, a relação de dependência com o mercado é maior no modelo influenciado pelos princípios do agronegócio, em que o estranhamento/alienação do trabalho se manifesta numa produção especializada, produtora de mercadorias, processo que dificulta a relação de identidade entre o produtor e seu produto. A dependência de um conjunto de técnicas introduzidas por uma lógica externa à da produção camponesa favorece o uso dos agrotóxicos e o adoecimento por meio deles.

$\mathrm{O}$ assentamento influenciado pelos princípios da agroecologia apresenta menor subordinação ao mercado, o que confere mais autonomia ao processo de trabalho. A relação com o movimento social, o consumo da produção, a maior preocupação com o ambiente e com a qualidade da alimentação da população conferem um aspecto parcial de combate ao estranhamento. A dependência de uma fonte de renda externa e as dificuldades encontradas em relação a direitos básicos atuam contraditoriamente no processo de (re)produção do assentamento, despertando sentimentos distintos, como por exemplo descrever o trabalho no assentamento como emancipador, mas não desejá-lo para um membro da família.

A análise do estranhamento/alienação se mostrou importante para nos aproximarmos da compreensão da indissociável relação subjetividade/objetividade, expressando como as relações materiais estabelecidas são determinantes na forma de adoecer e morrer dos assentados.

Apesar de as relações construídas segundo os princípios da agroecologia, a lógica agroecológica apresentarem um potencial emancipador, não há dúvidas ao afirmarmos que a superação plena dessa forma de estranhamento só se dará com a superação do modo de produção capitalista e a construção de uma sociedade que tenha como essência a emancipação humana. 


\section{Colaboradores}

Paulo Victor Rodrigues de Azevedo Lira e Pedro Costa Cavalcanti de Albuquqerque realizaram a coleta de dados e participaram de todas as etapas da pesquisa e da produção e revisão do artigo. Idê Gomes Dantas Gurgel participou da orientação da pesquisa e produção do texto.

Resumen Conocer cómo se organiza el proceso de trabajo en cualquier actividad productiva es esencial para entender el impacto en la salud de los trabajadores. Este conocimiento se asocia con la forma de organización de la sociedad, y puede resultar en el desarrollo del ser, sino contribuir a su alejamiento/alienación. En el estudio hemos tratado de entender cómo acontece la organización del proceso de trabajo de lo campesinado en dos asentamientos, influenciado por diferentes lógicas, la Agroindustria y la Agroecología, y su relación con lo alejamiento del trabajo y su impacto en la salud de los asentados. Se trata de un estudio de casos múltiples, con enfoque cualitativo, mediante entrevistas semiestructuradas y grupos focales. El estudio fue realizado entre los meses de enero e mayo de 2016, en dos asentamientos del Región Metropolitana de Recife, Pernambuco, Brasil. El procesamiento y análisis de los datos fue orientado por el procesamiento y el análisis de los datos siguieron una perspectiva que considera la totalidad e historicidad de las relaciones sociales y su articulación con los procesos sociales particulares. Los resultados muestran que la condición de alejamiento (y combatir) se produce de manera diferente en los dos asentamientos. Cuando la influencia de la agroindustria, presentado en una producción especializada, casi exclusivamente de mercancías y el uso intensivo de pesticidas. En cuanto a la influencia de la agroecología, tiene una producción diversificada, se suprime el uso de pesticidas y con menor intensidad en el trabajo. Palabras clave agroindustria; agricultura sostenible; plaguicidas; salud laboral; salud pública.

\section{Notas}

${ }^{1}$ Fundação Oswaldo Cruz, Centro de Pesquisas Aggeu Magalhães, Recife, Pernambuco, Brasil.

<paulo.alira@gmail.com>

Correspondência: Instituto Aggeu Magalhães, Laboratório Saúde, Ambiente e Trabalho. Av. Professor Moraes Rêgo, s/n, CEP 52171-011, Cidade Universitária, Recife, Pernambuco, Brasil.

${ }^{2}$ Fundação Oswaldo Cruz, Centro de Pesquisas Aggeu Magalhães, Recife, Pernambuco, Brasil. <pedro.calbuquerque@hotmail.com>

${ }^{3}$ Fundação Oswaldo Cruz, Centro de Pesquisas Aggeu Magalhães, Recife, Pernambuco, Brasil. <ideg@cpqam.fiocruz.br>

${ }^{4}$ Não há um consenso em relação à tradução das palavras Entfremdung e Entäusserung. Aqui estamos atribuindo Entfremdung para estranhamento/alienação, tidos como sinônimos, e Entäusserung para exteriorização, como traduzido por Lessa (2012). Apesar de o autor definir alienação (Entfremdung) e exteriorização (Entäusserung), também atribuiremos estranhamento como tradução da palavra Entfremdung, conforme traduzido por Ranieri 
em Marx (2010), Antunes (2011) e a versão traduzida pela editora Boitempo da ontologia do ser social (Lukács, 2013).

${ }^{5}$ Sobre o campesinato, concordamos com a análise de Oliveira (2007, p. 11, destaques no original): “(...) o campesinato e o latifúndio devem ser entendidos como de dentro do capitalismo e não de fora deste (...). O campesinato deve, pois, ser entendido como classe social que ele é. Deve ser estudado como um trabalhador criado pela expansão capitalista, um trabalhador que quer entrar na terra. O camponês deve ser visto como um trabalhador que, mesmo expulso da terra, com frequência a ela retorna, ainda que para isso tenha que (e)migrar (...) o processo contraditório de reprodução ampliada do capital, além de redefinir antigas relações de produção, subordinando-as à sua reprodução, engendra relações não capitalistas igual e contraditoriamente necessárias à sua reprodução."

${ }^{6}$ Como ressalta Netto (2010, p. 18), seguindo o pensamento marxiano, as categorias são expressões do modo de ser, determinações existenciais.

${ }^{7}$ Lukács argumenta a respeito de a ideologia ser sinônimo de 'falsa consciência': “Nesse caso, porém, trata-se de uma crítica da falsa consciência; contudo, em primeiro lugar, há muitas realizações da falsa consciência que jamais se converteram em ideologias e, em segundo lugar, aquilo que se converteu em ideologia de modo algum é necessária e simplesmente idêntico a falsa consciência. Por essa razão, só é possível compreender o que realmente é ideologia a partir de sua atuação social, a partir de suas funções sociais" (Lukács, 2013, p. 480).

\section{Referências}

ALBUQUERQUE, Guilherme S. C.; SILVA, Marcelo J. S. Sobre a saúde, os determinantes da saúde e a determinação social da saúde. Saúde em Debate, Rio de Janeiro, v. 38, n. 103, p. 953-965, out.-dez. 2014.

ANTUNES, Ricardo L. C. Adeus ao trabalho?: ensaio sobre as metamorfoses e a centralidade no mundo do trabalho. 15. ed. São Paulo: Cortez, 2011.

BARBOSA JÚNIOR, Sebastião A. A etnoveterinária no Assentamento Chico Mendes III: as relações dos camponeses e camponesas com os animais. 2013. 52f. Trabalho de Conclusão de Curso. (Graduação em Medicina Veterinária) - Universidade Federal Rural de Pernambuco, Recife, 2013.
BATISTELLA, Carlos. Abordagens contemporâneas do conceito de saúde. In: FONSECA, Angélica F.; CORBO, Anamaria D. (orgs.). O território e o processo saúde doença. Rio de Janeiro: EPSJV, 2007. p. 51-86.

BIANCHINI, Valter; MEDAETS, Jean P. P. Da revolução verde à agroecologia: Plano Brasil Agroecológico. Brasília: [s.n.], 2013. 21 p.

CAPORAL, Francisco R.; AZEVEDO, Edízio O. (orgs.). Princípios e perspectivas da agroecologia. Curitiba: Instituto Federal de Educação, Ciência e Tecnologia do Paraná/Educação a Distância, 2011.

CARNEIRO, Fernando F. et al. (orgs.). Dossiê Abrasco: um alerta sobre os impactos dos agrotóxicos na saúde. São Paulo: Expressão Popular, 2015. 
FARIA, Andréa A. C.; FERREIRA NETO, Paulo S. Ferramentas de diálogo: qualificando o uso das técnicas de DRP-Diagnóstico Rural Participativo. 2. ed. Brasília: IEB, 2006.

FREIRE, Paulo. Extensão ou comunicação? 8. ed. Rio de Janeiro: Paz e Terra, 1983.

GUZMÁN, Eduardo S.; MOLINA, Manuel G. Sobre a evolução do conceito de campesinato. 2. ed. São Paulo: Expressão Popular, 2013.

IASI, Mauro L. Ensaios sobre consciência e emancipação. 2. ed. São Paulo: Expressão Popular, 2011.

INSTITUTO BRASILEIRO DE GEOGRAFIA E ESTATÍSTICA (IBGE). Pesquisa agrícola municipal, 2011. Disponível em: <http:// www.sidra.ibge.gov.br $>$. Acesso em: 20 jan. 2016.

KOSIK, Karel. Dialética do concreto. 2. ed. Rio de Janeiro: Paz e Terra, 1976.

LAURELl, Asa. C.; NORIEGA, Mariano. Processo de produção e saúde: trabalho e desgaste operário. São Paulo: Hucitec, 1989.

LEAL NETO, Onicio B. et al. Análise espacial dos casos humanos de esquistossomose em uma comunidade horticultora da zona da mata de Pernambuco, Brasil. Revista Brasileira de Epidemiologia, São Paulo, v. 4, n. 15, p. 771-780, dez. 2012 .

LESSA, Sergio. Para compreender a ontologia de Lukács. 3. ed. São Paulo: Instituto Lukács, 2007.

LESSA, Sergio. Mundo dos homens: trabalho e ser social. 3. ed. São Paulo: Instituto Lukács, 2012.

LUKÁCS, György. Para uma ontologia do ser social II. São Paulo: Boitempo, 2013.

LUSTOSA, Maria G. O. P. Reforma agrária à brasileira: política social e pobreza. São Paulo: Cortez, 2012.
LUXEMBURGO, Rosa. A acumulação de capital: estudo sobre a interpretação econômica do imperialismo. Rio de Janeiro: Zahar Editores, 1970 .

MACHADO, Luiz C. P.; MACHADO FILHO, Luiz C. P. A dialética da agroecologia. São Paulo: Expressão Popular, 2014.

MARTINS, Adalberto M. Agroecologia: modelo que une alimentos saudáveis e luta pela reforma agrária. Revista Sem Terra: edição especial agroecologia, São Paulo, p. 36-37, 2009.

MARX, Karl. O capital. Livro I (capítulo VI Inédito). 1. ed. São Paulo: Livraria Editora Ciências Humanas, 1978.

MARX, Karl. Manuscritos econômico-filosóficos. São Paulo: Boitempo, 2010.

MAZALLA NETO, Wilon. Agroecologia e crítica da alienação: agricultores camponeses e a experiência do trabalho. In: NOVAES, Henrique; MAZIN, Ângelo D.; SANTOS, Laís. Questão agrária, cooperação e agroecologia. São Paulo: Outras Expressões, 2015. p. 231-262.

MINAYO, Maria C. S. O desafio do conhecimento: pesquisa qualitativa em saúde. 13. ed. São Paulo: Hucitec, 2013

MIRALHA, Wagner. Questão agrária brasileira: origem, necessidade e perspectivas de reforma hoje. Revista Nera, Presidente Prudente, v. 9, n. 8, p. 151-172, jan.-jun. 2006.

MOVIMENTO DOS TRABALHADORES RURAIS SEM TERRA (MST). Programa agrário do MST: texto produzido para o VI Congresso Nacional do MST. São Paulo: MST, 2014.

NETTO, José P. Introdução ao método da teoria social. 2010. Disponível em < https://pcb.org. br/portal/docs/int-metodo-teoria-social.pdf $>$. Acesso em: 5 maio 2016. 23 p.

NOVAES, Henrique; MAZIN, Ângelo D.; SANTOS, Laís (orgs.). Questão agrária, cooperação e agroecologia. São Paulo: Outras Expressões, 2015. 
NUNES DA SILVA, José N. et al. Transição agroecológica em assentamentos rurais: o processo inicial no Assentamento Chico Mendes III/PE-Brasil. Revista Brasileira de Agroecologia, Porto Alegre, v. 4, n. 2, p. 3.022-3.025, nov. 2009.

OLIVEIRA, Ariovaldo U. Geografia agrária: perspectivas no início do século XXI. In: OLIVEIRA, Ariovaldo U.; MARQUES, Marta I. M. (orgs.). O campo no século XXI: território de vida, luta e de construção da justiça social. São Paulo: Casa Amarela, Paz e Terra, 2004. p. 29-70.

OLIVEIRA, Ariovaldo U. Modo capitalista de produção, agricultura e reforma agrária. São Paulo: FFLCH; Labur, 2007.

PERNAMBUCO. Secretaria Estadual de Saúde. Secretaria Executiva de Vigilância em Saúde. Plano de ações para vigilância em saúde de populações expostas a agrotóxicos. Recife: Secretaria Estadual de Saúde, 2014.

PLEIN, Clério. Capitalismo, agricultura familiar e mercantilização. Informe Gepec, Toledo, v. 14, n. 2, p. 96-111, jul.-dez. 2010.

SARTORI, Vitor B. Lukács e a crítica ontológica ao direito. São Paulo: Cortez, 2010.

SILVA JÚNIOR, José P.; MACHADO, Maria R. I. M. Assentamentos de reforma agrária na zona canavieira de Pernambuco: monopolização das usinas nos territórios camponeses. In: ENCONTRO NACIONAL DE GEOGRAFIA AGRÁRIA, 19., São Paulo, 2009. Anais... São Paulo: FFLCH, 2009. p. 1-13.

SOUZA, José P. et al. Rendimento agronômico de consórcios entre pimentão e feijão-vagem arbustivo em sistema orgânico de cultivo. Comunicado Técnico 106, Seropédica, Embrapa Agrobiologia, 2007.

THOMAZ JÚNIOR, Antonio. A (des)ordem societária e territorial do trabalho. In: OLIVEIRA, Ariovaldo U.; MARQUES, Marta I. M. (orgs.). O campo no século XXI. São Paulo: Casa Amarela, Paz e Terra, 2004a. p. 71-86.

THOMAZ JÚNIOR, Antonio. Reestruturação produtiva do capital no campo, no século XXI, e os desafios para o trabalho. Pegada, Presidente Prudente, v. 5, n. 1-2, p. 9-30, 2004b.

WANDERLEY, Maria N. O camponês: um trabalhador para o capital. Caderno de Difusão de Tecnologia, Brasília, v. 2, n. 1, p. 13-78, jan.-abr. 1985.

Recebido em 03/10/2016. Aprovado em 03/07/2017. 